\title{
Effects of core Balance and Plyometric Training on Anaerobic Power and Dynamic Postural Stability in Youth Taekwondo Athletes
}

\author{
Buong-O Chun $\mathrm{PhD}^{1}$, Sang-Hyup Choi $\mathrm{PhD}^{2}$, Jong-Baek Lee $\mathrm{PhD}^{3}$, EonHo Kim $\mathrm{PhD}^{4}$, KiHyuk Lee $\mathrm{PhD}^{5}$ \\ ${ }^{1}$ Graduate School of Physical Education, Myongji University, Yongin; ${ }^{2}$ Center for Sport Science in Jeju, Jeju Special Self-Governing Provincial Sports Council, Jeju; ${ }^{3}$ Center \\ for Sport Science in Gangwon, Gangwon-do Sports Council, Chuncheon; ${ }^{4}$ Department of Physical Education, Dongguk University, Seoul; ${ }^{5}$ Department of Sport Culture, \\ Dongguk University, Seoul, Korea
}

PURPOSE: Muscle strength, power, speed, postural stability, and anaerobic power are important physical fitness factors required to perform well in a taekwondo competition. This study aimed to investigate the effects of 8 weeks of core balance and plyometric training on physical fitness in young taekwondo athletes.

METHODS: Nine young taekwondo athletes participated in this program. Body composition and relative fitness (muscle power, core strength, agility, postural stability, anaerobic power, and isokinetic muscle function) were measured before and after training. Data were analyzed using IBM SPSS Statistics version 23.0 (IBM Corp., Armonk, NY, USA). A paired t-test (pre vs. post) was used for the analysis.

RESULTS: The core strength measured by the sit-up count changed significantly after training $(p<.05)$. In case of postural stability, the right absolute reach distance in the Y-balance test improved significantly after training $(p<.05)$. In case of anaerobic power, the mean power $(p<.01)$ and the peak power $(p<.01)$ increased significantly after training.

CONCLUSIONS: We demonstrated that 8 weeks of core balance and plyometric training enhanced core strength, balance, and anaerobic power in young taekwondo athletes. Our results suggest that core balance and plyometric training are effective in improving muscle strength, core strength, balance, and anaerobic power.

Key words: Youth taekwondo athletes, Core balance, Plyometric, Anaerobic power, Postural stability

\section{INTRODUCTION}

Taekwondo athletes require relatively short durations of physical activity and explosive strength, thereby needing anaerobic power as well as aerobic capacity [1]. Taekwondo athletes' strength, muscular endurance, postural stability, flexibility, agility, and speed are important factors for improving performance, including accuracy and skill development [2,3]. Balance and speed are physical fitness factors that assist in providing power while maintaining stability during attack and defense [4]. In addition, flexibility is an essential factor for better performance of taekwondo athletes due to its role in expanding their range of motion, thereby helping in injury prevention. Moreover, the core muscles need to be improved for rapid body extension and alignment to allow for continuity of the next movement [5]. Differences in kicking and moving speeds during taekwondo competitions affect athletes' performance, and developing hip and lower extremity strength is required to continuously improve the attack power and speed. For taekwondo athletes, specific training that focuses on improving core and lower extremity strength is necessary for increasing the kicking speed and attack frequency [6,7].

The core is located at the center of the human body. Since core strength

Corresponding author: KiHyuk Lee Tel +82-2-2260-3417 Fax+82-2-2260-3741 E-mail lkhlikeanaver.com

*This study was conducted with the support of the Korea Institute of Sport Science (Korea Sports Promotion Foundation). We thank all subjects for participating in this study. Keywords Youth taekwondo athletes, Core balance, Plyometric, Anaerobic power, Postural stability

Received 19 Jan 2021 Revised 10 Feb 2021 Accepted 17 Feb 2021

@) This is an Open Access article distributed under the terms of the Creative Commons Attribution Non-Commercial License (https://creativecommons.org/licenses/by-nc/4.0// which permits unrestricted non-commercial use distribution, and reproduction in any medium, provided the original work is properly cited. 
is involved in the stability and balance of the body, strengthening the core muscle improves the body's stability and balance. In addition to maintaining a specific movement, the forces generated in the body are effectively transmitted to the limbs [8]. Therefore, core stabilization exercises are used to improve motility and stability, enhance trunk control ability by securing the center of gravity, and restore the human body to near the postural stability point by strengthening the deep muscles of the spine [9]. Stabilizing the core muscles is recommended for strengthening the center of the body because it connects the stimuli and responses in the body and induces coordination of the upper and lower bodies [10]. In particular, the importance of core muscle improvement is emphasized in taekwondo, which requires trunk stability. Sandrey and Mitzel reported that core balance training improved core endurance and balance ability [11]. A previous study demonstrated that [12] weeks of core stabilization enhanced the strength and muscular endurance of taekwondo Poomsae players, and improved the stability and balance control of the body [8].

On the other hand, plyometric training, a form of resistance exercise, is a training method that improves muscle strength and muscle power in the performance of most exercises or sports activities, by overloading an isotonic exercise and causing muscle reflex. This is strength training used to elicit faster and stronger forces during muscle contraction [12]. Plyometric training, which is widely practiced to improve athletes' performance, has been reported as a particularly useful training method for enhancing lower extremity muscle strength [13]. It is known to be effective in increasing postural stability, agility, maximal muscle strength, and muscle power $[14,15]$. This effect is due to the increase in muscle contractile force that promotes sensory function of the muscle nerve and expresses the energy stored in the muscle as kinetic energy $[16,17]$. Therefore, effective plyometric training is considered to be the primary training method for improving performance as it exercises the greatest strength for a short time and improves the momentary powerful and explosive force, such as the one involved in jumping. A previous study reported improvement in anaerobic exercise ability due to plyometric and weight training [18], and another study reported improved isokinetic lower extremity muscle strength, speed, and agility due to plyometric training [19].

Although most taekwondo training studies have analyzed physiological changes caused by taekwondo activities in obese children [20,21], efficient training for elite taekwondo athletes has not been fully elucidated. Some studies on the improvement of physical fitness following training mainly focused on the results of the analysis of the effects of a single training, such as an increase in stability by core training and improvement of anaerobic power by plyometric training $[8,22]$. Therefore, this study aimed to assess the improvement in physical strength and performance through the synergistic effect of core balance exercise and plyometric training in taekwondo athletes.

\section{METHODS}

\section{Participants}

The subjects of this study were nine elite taekwondo athletes from the Jeju N High School. This study was initiated after explaining the experiment process to all subjects in detail and obtaining their consent for participation and inspection regarding the conduct of various tests, according to the ethical principles of the Declaration of Helsinki. The physical characteristics of the study subjects are shown in Table 1.

\section{Measurements of body composition and physical fitness}

In this study, the variables were measured under the same conditions before and after the training to examine the effects of core balance and plyometric training on taekwondo athletes.

\section{1) Body composition}

Body composition was measured in terms of height, weight, and body fat percentage. Body fat percentage was measured using a body composition analyzer (Inbody-720, Biospace, Korea), before and after training Height was recorded in $0.1 \mathrm{~cm}$ units and body weight in $0.1 \mathrm{~kg}$ units.

\section{2) Muscle power}

The Sargent Jump test was performed to assess muscle power. At the footboard of the equipment (ST-150, Seed Tech, Korea), the subject was

Table 1. Characteristics of the Subject

\begin{tabular}{lccccc}
\hline Variable & N & Age $(\mathrm{yr})$ & Height $(\mathrm{cm})$ & Weight $(\mathrm{kg})$ & Career $(\mathrm{month})$ \\
\hline Pre & 9 & $17.56 \pm 0.53$ & $177.60 \pm 5.71$ & $70.79 \pm 10.45$ & $12.70 \pm 2.30$ \\
Post & 9 & $17.56 \pm 0.53$ & $177.85 \pm 6.23$ & $72.02 \pm 10.51$ & $13.17 \pm 1.76$ \\
\hline
\end{tabular}

Values are mean (SD). 
allowed to jump as high as possible with the legs open and the knees extended during the jump. A total of two sessions were conducted and the best records were selected.

\section{3) Core strength}

In accordance with previous studies' reports [23], core strength was assessed through sit-ups. The subjects were made to sit upright, bend their knees at a 90 degree angle, and fix their feet such that the upper body was in full contact with the back. The test was performed for 1 minute and count numbers were recorded.

\section{4) Agility}

Agility was assessed using the side-step test (ST-110, Seed Tech, Korea). The participants were placed on the center line and made to perform a side step at the 'start' signal. The participants were instructed to conduct the movement as fast as possible for 20 seconds. The response time was used as a systemic response meter (ST-140, Seed Tech, Korea). Participants had their knees bent lightly $\left(120-160^{\circ}\right)$ on the reaction plate. The time of the participants leaving the reaction board upon perceiving the visual stimulus was measured. The test was conducted twice in a total of $0.001 \mathrm{~s}$ to determine the fastest time.

\section{5) Postural stability}

The Y-balance test evaluated postural stability. Barefoot standing at the foot of the measuring equipment was measured in a total of six directions, including the anterior, posteromedial, and posterolateral directions of the left and right sides. Deviation from the center in the measurement, failure to return to the starting position, and foot contact with the ground or kicking were considered fouls. For accurate measurement, a previous study was referred [24]. The total distance of the left and right values was calculated by measuring the anterior, posterior medial, and posterior lateral values. The exact formula is as follows: Total distance $=$ $($ anterior + posteromedial + posterolateral $) / 3$.

\section{6) Anaerobic power}

The Wingate anaerobic test was used to evaluate anaerobic power, using a cycle ergometer (894 E, Monark, Sweden). The Wingate test was conducted using widely adopted standard methods [25]. Participants performed light pedaling for 1 minute as a warm-up, and pedaled for 30 seconds at the 'start' signal. Through this procedure, the peak power (W/ $\mathrm{kg}$ ), mean power $(\mathrm{W} / \mathrm{kg})$, and fatigue index (\%) were measured.

\section{7) Isokinetic knee muscle function}

Isokinetic knee muscle function was measured using isokinetic dynamometers (Humac Norm, CSMi, Stoughton, MA, USA), to measure the isokinetic strength and power of the extensor and flexors of the knee. The isokinetic strength was measured at $60 \%$ of angular velocity, and power was measured at $180 \%$ s of angular velocity.

\section{Core balance and plyometric training}

The training conducted in this study focused on training to improve specific fitness factors, such as core balance, anaerobic power, and isokinetic knee muscle function, in taekwondo athletes. We analyzed the training content of the taekwondo team with the help of officials and experts and composed an exercise program to strengthen core balance, anaerobic power, and isokinetic muscle function [26].

Subjects participated in 60-minute sessions, twice a week for 8 weeks, Warm-up and cool-down activities were performed for 5 minutes each, and core balance and plyometric training was performed for 50 minutes. Gymnastic and stretching exercises were performed as the warm-up and cool-down activities. The intensity and rest of the training were as follows: 5 minutes per set for 3 sets at 60-80\% intensity for weeks 1-2; 4 minutes per set for 3 sets at $80-100 \%$ intensity for weeks 3-5; and 3 minutes per set for 4 sets at $85-100 \%$ intensity for weeks 6-8 (Table 2).

\section{Statistical analysis}

The values of all measured variables were presented as mean and standard deviation using SPSS Windows 23.0 (SPSS, Inc., Chicago, IL, USA). The effects of the training were assessed by using paired t-tests to compare pre- and post-training values. The statistical significance level was set at $\alpha=.05$.

\section{RESULTS}

\section{The change in muscle power and core strength due to core balance and plyometric training}

The results of the comparison between muscle function pre- and posttraining are shown in Table 3. There was no significant difference in muscle power pre- and post-training, but there was a significant difference in core muscle strength $(p<.01)$. 
Table 2. Composition of core balance and plyometric training

\begin{tabular}{|c|c|c|}
\hline Variables & Method & $\begin{array}{l}\text { Frequency and time } \\
\text { (3 sets) }\end{array}$ \\
\hline \multicolumn{3}{|l|}{ Core balance } \\
\hline 1) Plank & Put elbows on the floor, lift knees, and straighten body & Over 60 seconds \\
\hline 2) Plank twist & In plank, turn the pelvis and touch the mat with the left and right pelvis & 20 times \\
\hline 3) Side crunch & In crunch, elbow and knee twist in opposite directions & $15-20$ times \\
\hline 4) Side plank with leg lift & Put one hand on the ground, position diagonally and lift legs & 40 seconds \\
\hline 7) Airborne Lunge & $\begin{array}{l}\text { Stand up with one leg on the other side in a lunge position, sit up without touching the ground } \\
\text { and repeat }\end{array}$ & $12-15$ times \\
\hline \multicolumn{3}{|c|}{ ( } \\
\hline 1) Double leg tuck jump & Jumping both legs simultaneously using knee recoil & 10-12 times \\
\hline 2) Pike jump & Put both feet at the same time and stretch forward to jump & 10-12 times \\
\hline 5) Cone hops & Stand the cone at regular intervals and then jump over the cone (8-10) & 1 time \\
\hline 6) Stride jump crossover & Jump with both leg crossed at the same time & $12-15$ times \\
\hline 7) Barrier jumps & Jump over the box & 10-12 times \\
\hline 8) Box jump & Jump from ground to box & 10-12 times \\
\hline 9) Depth jump & Jump from the box to the ground, again jumping & 10-12 times \\
\hline 10) Turning reverse lunge & Change direction to conduct lunge & 20 times 3 sets \\
\hline 11) Backward lunge & Lift the legs forward to conduct lunges in the rear direction & 20 times 3 sets \\
\hline 12) Zigzag lunge & Conduct a lunge in a zigzag direction $20-30 \mathrm{~m}$ (50m after adjusting position) & Round 2 times \\
\hline
\end{tabular}

\section{The change in agility and postural stability due to core balance and plyometric training}

The results of the comparison between agility and balance pre- and post-training are shown in Tables 4 and 5 . There was no significant difference in agility. Regarding postural stability, there was a significant difference between the Y-balance test's right total reach $(p<.05)$, pre- and post-training.

\section{The change in anaerobic power due to core balance and plyometric training}

Table 6 shows the results of the comparison between anaerobic power pre- and post-training. Anaerobic power was significantly different preand post-training for both mean power $(p<.01)$ and peak power $(p<.01)$.

\section{The change in isokinetic knee muscle function due to core balance and plyometric training}

The results of the comparison between isokinetic knee muscle function pre- and post-training are shown in Table 7. There was no significant difference in either isokinetic strength or power.

\section{DISCUSSION}

The purpose of this study was to analyze the effects of 8 weeks of core balance and plyometric training on the physical fitness of youth elite taekwondo athletes. The results showed positive changes in muscle power, core strength, agility, postural stability, and anaerobic power after core balance and plyometric training.

A previous study on the change in fitness levels due to core muscle training reported improvements in strength, endurance flexibility, and balance [27]. Another previous study reported that core stabilization training had positive effects on speed and agility, and on anaerobic power [28]. In addition, Ozmen and Aydogmus reported improved agility and balance due to a combination of core training in adolescent badminton players [29]. Postural stability (i.e., the ability to maintain the stability of the body) is an essential element in performing proper physical activity and exercise. The stabilization of the core region is closely related to the development of balance. Strengthening the muscles of the abdomen, lumbar spine, pelvis, and buttocks results in a stable control of the trunk area, thus leading to an improvement in exercise performance and prevention of sports injuries [30]. Maintaining and controlling the hu- 
Table 3. Changes in muscle function due to core balance and plyometric training

\begin{tabular}{lccccc}
\hline Variable & $\mathrm{N}$ & Pre & Post & $\mathrm{t}$ & $p$ \\
\hline $\begin{array}{l}\text { Muscle power } \\
\quad \text { Sargent jump }(\mathrm{cm})\end{array}$ & 9 & $60.89 \pm 4.31$ & $62.11 \pm 3.89$ & -2.052 & .074 \\
$\begin{array}{l}\text { Core strength } \\
\quad \text { Sit-up (rep/1 min) }\end{array}$ & 9 & $55.11 \pm 6.64$ & $62.11 \pm 5.93$ & -3.934 & $.004^{* *}$ \\
\hline
\end{tabular}

Values are mean (SD).

${ }^{*} p<.01$.

Table 4. Changes in agility due to core balance and plyometric training

\begin{tabular}{lllllc}
\hline Variable & N & Pre & Post & t & $p$ \\
\hline Side step (rep/20 sec) & 9 & $45.22 \pm 5.04$ & $46.78 \pm 1.79$ & -.894 & .398 \\
Reaction time (light/sec) & 9 & $0.230 \pm 0.010$ & $0.229 \pm 0.008$ & .108 & .917 \\
\hline
\end{tabular}

Values are mean (SD).

Table 5. Change in dynamic balance due to core balance and plyometric training

\begin{tabular}{llllll}
\hline Variable & N & Pre & Post & t & $p$ \\
\hline Y-balance test & & & & & \\
$\quad$ Left absolute reach distance $(\mathrm{cm})$ & 9 & $87.74 \pm 12.24$ & $91.30 \pm 5.43$ & -0.892 & .398 \\
Right absolute reach distance $(\mathrm{cm})$ & 9 & $87.56 \pm 4.44$ & $90.15 \pm 6.12$ & -2.535 & $.035^{*}$ \\
\hline
\end{tabular}

Values are mean (SD).

${ }^{*} p<.05$.

man body play an important role in the performance of activities of daily living and functional movement. They are affected by neurological factors, such as proprioceptive sensation, vestibular sensation, postural alignment, and muscle strength through the musculoskeletal system [31]. Measuring changes pre- and post-core balance training in our study showed that the right total distance in the Y-balance test increased significantly after training.

Plyometric training conducted to improve athletes' performance leads to an effective improvement in muscle function in a short time. Chimere et al. reported improvement in maximum strength with 6 weeks of plyometric training [32]. Another study reported that plyometric training had a positive effect on muscle strength and speed, as well as a significant effect on the leap force [33]. Plyometric training results in rapid shortening of contraction after elongation, which is the principle behind isotonic contraction, thus reducing the gap between muscle strength and muscle power and improving agility and speed $[34,35]$. Our study found that plyometric training led to an increase in core strength, along with increase in muscle power and agility. Therefore, in order to maintain strong kicking and rapid movements during taekwondo competitions, plyometric training is considered to be a necessary training method. On the other hand, the isokinetic knee strength and power, a subfactor of professional fitness, did not show any significant difference. Particularly for taekwondo, where explosive speed, lower leg muscle power improvement, and rapid attack and defense must be performed simultaneously, plyometric training is considered to be a suitable training method [22]. In addition, the hybrid training method in this study resulted in a significant change in the mean and peak values of the anaerobic power. Furthermore, a previous study showed significantly improved peak power of the anaerobic capacity through plyometric training in soccer and basketball players $[36,37]$. This result was similar to the results of our study.

This study was conducted to confirm the effects of core balance and plyometric training, but there were some limitations. First, a control group was not set up and compared with the training group, to confirm the effect of training. However, the subjects of this study were elite taekwondo athletes with more than 7 years of experience, and, unlike ordinary people, they are athletes who had been training regularly, even before this training. In addition, previous studies have also evaluated the effects of training without comparison with a control group [38]. Second, this study resulted in significant improvement in some limited fitness factors over a relatively short period of 8 weeks of training. If the training is conducted for more than 8 weeks, significant improvements can 
Table 6. Changes in anaerobic power due to core balance and plyometric training

\begin{tabular}{llrrrr}
\hline Variable & $\mathrm{N}$ & Pre & Post & $\mathrm{t}$ & $p$ \\
\hline Fatigue index (\%) & 9 & $53.07 \pm 4.48$ & $54.72 \pm 6.56$ & -1.095 & .305 \\
Mean power (W/kg) & 9 & $6.40 \pm 0.83$ & $6.98 \pm 0.87$ & -4.301 & $.003^{* *}$ \\
Peak power (W/kg) & 9 & $8.43 \pm 1.09$ & $9.17 \pm 1.06$ & -4.175 & $.003^{* *}$ \\
\hline
\end{tabular}

Values are mean (SD).

${ }^{* *} p<.01$.

Table 7. Changes in isokinetic knee strength due to core balance and plyometric training

\begin{tabular}{|c|c|c|c|c|c|}
\hline Variable & $\mathrm{N}$ & Pre & Post & $\mathrm{t}$ & $p$ \\
\hline Left extensor strength (\%BW) & 9 & $256.97 \pm 35.35$ & $262.82 \pm 28.25$ & .222 & .830 \\
\hline Left flexor strength (\%BW) & 9 & $153.06 \pm 12.27$ & $147.76 \pm 23.75$ & .757 & .471 \\
\hline Right extensor strength (\%BW) & 9 & $262.89 \pm 28.25$ & $264.44 \pm 36.71$ & -.137 & .894 \\
\hline Right flexor strength (\%BW) & 9 & $156.12 \pm 19.22$ & $161.36 \pm 24.31$ & -.914 & .387 \\
\hline Left extensor power (\%BW) & 9 & $270.11 \pm 36.12$ & $284.38 \pm 42.17$ & -1.157 & .281 \\
\hline Left flexor power (\%BW) & 9 & $220.26 \pm 30.68$ & $214.20 \pm 32.55$ & .668 & .523 \\
\hline Right extensor power (\%BW) & 9 & $277.29 \pm 26.29$ & $284.52 \pm 34.23$ & -.689 & .511 \\
\hline Right flexor power (\%BW) & 9 & $214.10 \pm 40.56$ & $220.70 \pm 27.44$ & -.637 & .542 \\
\hline
\end{tabular}

be expected. In future studies, it will be necessary to examine the effect of training for a period of more than 8 weeks.

\section{CONCLUSION}

In this study, 8 weeks of core balance and plyometric training showed improvements in the core strength, postural stability, and anaerobic power of taekwondo athletes. Thus, if this training is conducted with the athletes in preparation for important competitions, it could improve their performance in a short time.

\section{CONFLICT INTEREST}

The authors declare that they have no competing interests.

\section{AUTHOR CONTRIBUTIONS}

Conceptualization: KH Lee; Data curation: SH Choi; Formal analysis: BO Chun, JB Lee; Methodology: SH Choi, KH Lee; Project administra- tion: SH Choi, KH Lee; Visualization: JB Lee, KH Lee; Writing-original draft: KH Lee; Writing-review \& editing: BO Chun, EH Kim, KH Lee.

\section{ORCID}

Buong-O Chun

Sang-Hyup Choi

Jong-Baek Lee

EonHo Kim

Kihyuk Lee https://orcid.org/0000-0003-3831-2328

https://orcid.org/0000-0003-1166-864X https://orcid.org/0000-0001-8276-2057 https://orcid.org/0000-0002-1907-390X https://orcid.org/0000-0001-6717-7087

\section{REFERENCES}

1. Sadowski J, Gierczuk D, Miller J, Cieśliński, I, Buszta, M. Success factors in elite WTF taekwondo competitors. Arch Budo. 2012;8(3):141-6.

2. Sarmet Moreira PV, Crozara LF, Goethel MF, de Paula LV, Vieira F.

Talent detection in taekwondo: which factors are associated with the longitudinal competitive success?. Arch Budo. 2014;10:295-306.

3. Arazi H, Hosseinzadeh Z, Izadi M. Relationship between anthropo- 
metric, physiological and physical characteristics with success of female taekwondo athletes. Turk J Sport Exerc. 2016;18(2):69-75.

4. Fong SS, Fu SN, Ng GY. Taekwondo training speeds up the development of balance and sensory functions in young adolescents. J Sci Med Sport. 2012;15(1):64-8.

5. Steffen K, Engebretsen L. More data needed on injury risk among young elite athletes. Br J Sports Med. 2010;44(7):485-9.

6. Ke-tien Y. Training periodization in lower limb performance and neuromuscular controlling in taekwondo athletes. Life Sci J. 2012;9(3):850-7.

7. Moreira P, Franchini E, Ervilha U, Goethel M, Cardozo A, et al. Relationships of the expertise level of taekwondo athletes with electromyographic, kinematic and ground reaction force performance indicators during the dollyo chagui kick. Arch Budo. 2018;14:59-69.

8. Bagherian S, Ghasempoor K, Rahnama N et al. The effect of core stability training on functional movement patterns in college athletes. J Sport Rehabil. 2019;28(5):444-9.

9. Yang DS. Effects of 12 weeks core stability training on physical fitness and stability in taekwondo poomsae players. A J Kinesiol. 2014;16(3): 59-67.

10. Sung DJ, Park SJ, Kim S, Kwon MS, Lim YT. Effects of core and nondominant arm strength training on drive distance in elite golfers. J Sport Health Sci. 2016;5(2):219-25.

11. Sandrey MA, Mitzel JG. Improvement in dynamic balance and core endurance after a 6-week core-stability-training program in high school track and field athletes. J Sport Rehabil. 2013;22(4):264-71.

12. Bogdanis GC, Tsoukos A, Kaloheri O, Terzis G, Veligekas P, Brown LE. Comparison between unilateral and bilateral plyometric training on single- and double-leg jumping performance and strength. J Strength Cond Res. 2019;33(3):633-40.

13. Sáez-Sáez de Villarreal E, Requena B, Newton RU. Does plyometric training improve strength performance? a meta-analysis. J Sci Med Sport. 2010;13(5):513-22.

14. Thomas K, French D, Hayes PR. The effect of two plyometric training techniques on muscular power and agility in youth soccer players. J Strength Cond Res. 2009;23(1):332-5.

15. Ramírez-Campillo R, Gallardo F, Henriquez-Olguín C, Meylan CM, Martínez C, et al. Effect of vertical, horizontal, and combined plyometric training on explosive, balance, and endurance performance of young soccer players. J Strength Cond Res. 2015;29(7):1784-95.

16. Skurvydas A, Brazaitis M. Plyometric training does not affect central and peripheral muscle fatigue differently in prepubertal girls and boys.
Pediatr Exerc Sci. 2010;22(4):547-56.

17. Behrens M, Mau-Moeller A, Bruhn S. Effect of plyometric training on neural and mechanical properties of the knee extensor muscles. Int J Sports Med. 2014;35(02):101-19.

18. Zearei H, Ramezanpour MR, Pakdelan S. Comparison of the effect of plyometric and resistance training on explosive power and speed in female taekwondo players. J Basic Appl Sci Res. 2013;3:339-43.

19. Adigüzel NS, Günay M. The effect of eight weeks plyometric training on anaerobic power, counter movement jumping and isokinetic strength in 15-18 years basketball players. Int J Environ Sci Educ. 2016;11(10): 3241-50.

20. Jung HC, Lee S, Kang H, Seo MW, Kim, HB, et al. Taekwondo training improves CVD risk factors in obese male adolescents. Arch Budo. 2016;12:85-92.

21. Lee S, Hong G, Park S. The effect of taekwondo training on physical fitness and the allergic response factor of hypersensitive obese children. Arch Budo. 2018;14:113-21.

22. Monks L, Seo MW, Kim HB, Jung HC, Song JK. High-intensity interval training and athletic performance in taekwondo athletes. J Sports Med Phys Fitness. 2017;57(10):1252-60.

23. Bianco A, Jemni M, Thomas E, Patti A, Paoli A, et al. The sit up test to exhaustion as a test for muscular endurance evaluation. Int J Occup Med Environ Health. 2015;28(3):445-78.

24. Plisky PJ, Gorman PP, Butler RJ, Kiesel KB, Underwood FB, et al. The reliability of an instrumented device for measuring components of the star excursion balance test. N Am J Sports Phys Ther. 2009;4(2):92-9.

25. Nikolaïdis P. Anaerobic power across adolescence in soccer players. Human Movement. 2011;12(4):342-7.

26. Davies G, Riemann BL, Manske R. Current concepts of plyometric exercise. Int J Sports Phys Ther. 2015;10(6):760-6.

27. Sekendiz B, Cug M, Korkusuz F. Effects of Swiss-ball core strength training on strength, endurance, flexibility, and balance in sedentary women. J Strength Cond Res. 2010;24(11):3032-40.

28. Mendes B. The effects of core training applied to footballers on anaerobic power, speed and agility performance. Anthropol. 2016;23(3):3616.

29. Ozmen T, Aydogmus M. Effect of core strength training on dynamic balance and agility in adolescent badminton players. J Bodyw Mov Ther. 2016;20(3):565-70.

30. Cissik JM. The role of core training in athletic performance, injury prevention, and injury treatment. Strength Cond J. 2011;33(1):10-5. 
31. McGill S. Core training: Evidence translating to better performance and injury prevention. Strength Cond J. 2010;32(3):33-46.

32. Chimera NJ, Swanik KA, Swanik CB, Straub SJ. Effects of plyometric training on muscle-activation strategies and performance in female athletes. J Athl Train. 2004;39(1):24-31.

33. Campo SS, Vaeyens R, Philippaerts RM, Redondo JC, de Benito AM, et al. Effects of lower-limb plyometric training on body composition, explosive strength, and kicking speed in female soccer players. J Strength Cond Res. 2009;23(6):1714-22.

34. Miller MG, Herniman JJ, Ricard MD et al. The effects of a 6-week plyometric training program on agility. J Sports Sci Med. 2006;5(3): 459.

35. Taheri E, Nikseresht A, Khoshnam E. The effect of 8 weeks of plyometric and resistance training on agility, speed and explosive power in soccer players. Eur J Exp Biol. 2014;4(1):383-6.

36. Khodajo AR, Nikseresht A, Khoshnam E. The effect of strength and plyometric training on anaerobic power, explosive power and strength quadriceps femoris muscle in soccer players. Eur Journal of Experimental Biology. 2014;4(1):448-51.

37. Adigüzel NS, Günay M. The effect of eight weeks plyometric training on anaerobic power, counter movement jumping and isokinetic strength in 15-18 years basketball players. Int J Environ Sci Educ. 2016;11(10): 3241-50.

38. Marques MC, Tillaar Rv, Vescovi JD, González-Badillo JJ. Changes in strength and power performance in elite senior female professional volleyball players during the in-season: a case study. J Strength Cond Res. 2008;22(4):1147-55. 